\title{
The Process of Dispersing Bismuth Atoms into Iridium via an Intermediate Monolayer of Graphite
}

\author{
Arif Orujov, Isfandiyar Aliyev \\ Baku State University, Baku, Azerbaijan \\ Email: orar@mail.ru
}

Received 30 November 2015; accepted 18 January 2016; published 22 January 2016

Copyright (C) 2016 by authors and Scientific Research Publishing Inc.

This work is licensed under the Creative Commons Attribution International License (CC BY). http://creativecommons.org/licenses/by/4.0/

(c) () Open Access

\section{Abstract}

It is first revealed by thermodesorption spectroscopy that when bismuth atoms diffuse the indium atoms through an intermediate graphite layer, they show certain characteristic features. In the Ir (111)-C system at $1400 \mathrm{~K}<T<1600 \mathrm{~K}$, we witness the most strong form of diffusion of bismuth into iridium. It has been found that the fractions of the fluxes of intercalation equal to $\delta=0.4 \pm$ 0.05 and diffusion $\delta_{\mathrm{Bi}}=N_{\mathrm{dif}} / N=2.5 \times 10^{-3}$ bismuth atoms in the $\operatorname{Ir}(111)-C$ system. The amount of intercalated and diffused bismuth depends on the electrical field, i.e., on the positive potential in the Ir(111)-C system. It has been noted that a considerable diffusion of bismuth into iridium started at $180 \mathrm{~V}$ and increased up to $3000 \mathrm{~V}$. The activation energies for bismuth diffusion into and from iridium were calculated to be $E_{n 1}=6.05 \pm 0.05 \mathrm{eV}$ and $E_{1 n}=6.3 \pm 0.1 \mathrm{eV}$, respectively.

\section{Keywords}

\section{Surface Ionization, Graphite Monolayer, Intercalation, Diffusion}

\section{Introduction}

The investigation of the diffusion of sodium, potassium, cesium, samarium, and barium atoms into iridium via an intermediate graphite monolayer [1]-[6] demonstrates that the diffusion process depends both on the ionic state of atoms on the Ir-C surface as well as the state of the external electronic shell and the valence of the element. $\mathrm{Na}, \mathrm{K}$, and $\mathrm{Cs}$ are the group I elements with the ground states of the valence electrons $3 s^{1}, 4 s^{1}$, and $6 s^{1}$, respectively. The ground state of the samarium external shell is $4 f^{6} 6 s^{2}$, and for Ba, the Group II element, $6 s^{2}$. Bismuth is the Group V element with the ground state of the valence electron $4 \mathrm{f}^{14} 5 \mathrm{~d}^{10} 6 \mathrm{~s}^{2} 6 \mathrm{p}^{3}$; from the perspective of interaction with the $\operatorname{Ir}(111)$ and $\operatorname{Ir}(111)-C$ surfaces, it holds an intermediate position among K, Cs, and Ba. 
The ionization potential of bismuth is higher than that of $\mathrm{Na}$ and $\mathrm{Ba}$. As a consequence, it is essential to study bismuth diffusion into iridium upon the irradiation of the Ir-C system by a flux of bismuth atoms. The main purpose of this work is to study the diffusion of bismuth atoms in the $\operatorname{Ir}(111)-C$ system, determination of the activation energy of bismuth diffusion into and from iridium, as well as to determine the concentration of diffused atoms compared to other elements.

\section{Experimental}

The measurements were conducted in an ultra-high vacuum magnetic mass spectrometer of sector type with the angle of deflection of the ion trajectory equal to $90^{\circ}$ at a residual pressure of $1 \times 10^{-10}$ Torr. A detailed description of the experimental setup is presented elsewhere [1]-[7]. Iridium was taken in the form of a thin textured tape $50 \times 1.5 \times 0.3 \mathrm{~mm}^{3}$ with the major face (111) having the work function $\varphi=5.8 \mathrm{eV}$ [8]. The graphite monolayer was obtained by exposure of iridium heated to $1750 \mathrm{~K}$ in benzene vapors at a partial pressure from $10^{-4}$ to $10^{-6}$ Torr. The benzene molecules $\mathrm{C}_{6} \mathrm{H}_{6}$ do not dissociate on the valence saturated surface of the graphite monolayer and, therefore, do not modify its thickness. Bismuth was sprayed onto the Ir-C surface from a Knudsen cell, and its state in the adlayer was studied by the method of thermal desorption spectroscopy (TDS) in the flash thermal desorption mode with the mass spectrometric registration of the current of Bi ions. In order to reveal intercalated bismuth, the flash was performed at the rate of $100 \mathrm{~K} / \mathrm{s}$ up to $2300 \mathrm{~K}$ (lower than the melting point $2683 \mathrm{~K}$ of the iridium tape) and then the current of Bi ions was recorded at a constant $T$. Every time at so high a temperature, graphite islands in the adlayer on iridium become dissolved carbon flies away, and the freed intercalated and diffused atoms are desorbed in the form of $\mathrm{Bi}^{+}$ions. The neutral component of the flux desorbed during the flash was ionized in an electron impact source before the entrance into the mass analyzer. The data related to the thermo ionic emission and dissociation of $\mathrm{CsCl}$ molecules were also utilized for the surface analysis.

\section{Results and Discussion}

Over the process of irradiation of $\operatorname{Ir}(111)$-C heated by a flux of bismuth atoms, with a flux density of $v=\left(10^{10}\right.$ $\left.10^{14}\right) \mathrm{sm}^{-2} \cdot \mathrm{s}^{-1}$, to $T \leq 1800 \mathrm{~K}$, there was observed an intercalation of bismuth atoms into the graphite monolayer on iridium and diffusion of bismuth into iridium. As the flux increased from $10^{10}$ to $10^{14} \mathrm{sm}^{-2} \cdot \mathrm{s}^{-1}$, the amount of intercalated bismuth increased linearly (Figure 1). The amount of diffused bismuth increased strongly at high fluxes of $v=\left(10^{13}-10^{14}\right) \mathrm{sm}^{-2} \cdot \mathrm{s}^{-1}$ and sufficiently high temperatures of Ir-C $(T=1400-1600 \mathrm{~K})$. Upon irradiation of $\operatorname{Ir}(111)$-C heated to $T=1600 \mathrm{~K}$ by a flux of bismuth atoms with a high density of $v \approx 10^{14} \mathrm{sm}^{-2} \cdot \mathrm{s}^{-1}$ in $t=$

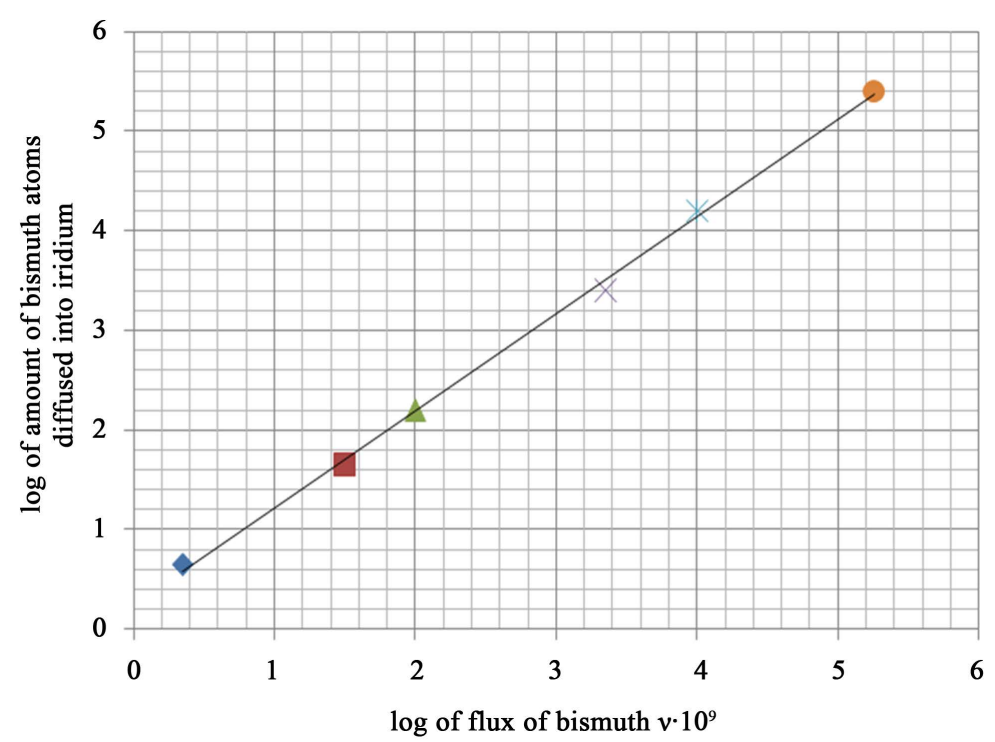

Figure 1. Logarithm of the amount (number) $N$ of intercalated bismuth atoms as a function of the logarithm of the flux of bismuth atoms, $\log \left(N \times 10^{-9}\right)=f\left(\log \left(\nu \times 10^{-9}\right)\right)$. 
5, 10, 15 min, etc., the amount of intercalated bismuth was hundreds times lower than that in the diffusion zone. The length of the diffusion phase was also significantly higher than that of the bismuth intercalation phase. The thermal desorption of $\mathrm{Bi}^{+}$ions from the $\operatorname{Ir}(111)-\mathrm{C}$ system started at $1800 \mathrm{~K}$, i.e., before the vaporization of the graphite monolayer. With an increase in the exposure temperature of Ir-C from 1600 to $1800 \mathrm{~K}$, the amount of diffused bismuth decreased. The most intensive diffusion of bismuth into iridium occurred at $T=1400-1600 \mathrm{~K}$ in the $\operatorname{Ir}(111)-C$ system. From a comparison of the amount of bismuth atoms $N=v t$ incident onto the $\operatorname{Ir}(111)-C$ surface heated to $T=1600 \mathrm{~K}$ in a time $t$ with the amount of bismuth diffusing from iridium as determined by the TDS analysis of $\mathrm{Bi}^{+}$ions, we found that the fraction of the flux of bismuth atoms diffusing into iridium is $\delta_{\mathrm{Bi}}=\approx$ $2 \times 10^{-3}$. The fraction of the flux of bismuth atoms diffusing into iridium was determined from the comparison of the $\mathrm{Cs}^{+}$and $\mathrm{Bi}^{+}$ions thermal desorbed from $\operatorname{Ir}(111)-\mathrm{C}$ using the known value $\delta_{\mathrm{Cs}}=0.25$ [2]. Under equal conditions of exposure of Ir-C in the fluxes of bismuth and cesium atoms, the ratio of the amounts of diffusing atoms can be determined as the ratio of the fraction of the fluxes of $\mathrm{Bi}$ and $\mathrm{Cs}$ diffusing into iridium: From the comparison of the areas under the TDS peaks of $\mathrm{Bi}^{+}$and $\mathrm{Cs}^{+}$ions, we found that $\gamma_{\mathrm{In}} \approx 5 \times 10^{-3}$. Then, $\delta_{\mathrm{Bi}} \approx 1.25 \times 10^{-3}$, which is in good agreement with the above-mentioned estimate of $\delta_{\mathrm{Bi}}$ into iridium. From the TDS analysis of $\mathrm{Bi}^{+}$ ions arising upon the electrons ionization of the flux of bismuth atoms desorbed from the iridium surface and from the Ir-C system, we determined the fraction in a flux of bismuth atoms characteristic of those atoms that pass into the intercalated state under the graphite monolayer on iridium at room temperature. To do this, we recorded the amount of $\mathrm{Bi}^{+}$ions thermo desorbed from the iridium surface in a definite time of irradiation of the iridium tape by the flux of bismuth atoms with a definite density. Then, under the same conditions, we irradiated $\operatorname{Ir}(111)-C$ and again recorded the amount of thermo desorbed bismuth ions. From the comparison of the area under the peak from the bismuth atoms thermo desorbed from the iridium with the area under the peak correspondent to the intercalated atoms thermo desorbed from $\operatorname{Ir}(111)-\mathrm{C}$, we found the fraction of the flux of intercalated bismuth atoms in the $\operatorname{Ir}(111)-C$ system to be $\bar{\delta}=0.35 \pm 0.05$. Thus, at room temperature from the flux of bismuth atoms falling onto $\operatorname{Ir}(111)$-C only approximately one of three bismuth atoms becomes intercalated into the graphite monolayer. From the TDS analysis it follows that the amount of the bismuth atoms desorbed from the iridium surface is equal to the sum of the bismuth atoms desorbed from the $\operatorname{Ir}(111)$-C surface, on the one hand, and the indium atoms intercalated upon the preliminary irradiation of $\operatorname{Ir}$ and $\operatorname{Ir}(111)$-C by this flux within the same exposure time, on the other. This demonstrates that at room temperature it is possible to neglect the diffusion of bismuth atoms into iridium. The TDS analysis of $\mathrm{Bi}^{+}$ions showed that at the irradiation of $\operatorname{Ir}(111)-$ C heated to $T \leq 1600 \mathrm{~K}$ by a flux of bismuth atoms with a density of $v \approx 10^{14} \mathrm{sm}^{-2} \cdot \mathrm{s}^{-1}$ the amount of intercalated and diffused bismuth atoms depends on the positive potential of $\operatorname{Ir}(111)-C$, i.e., on the electric field. The noticeable diffusion of bismuth into iridium started at $180 \mathrm{~V}$ and increased with increasing field up to $3000 \mathrm{~V}$. For instance, as the voltage increased from $180 \mathrm{~V}$ to $3000 \mathrm{~V}$ the amount of intercalated bismuth increased by a factor of three, while the amount of diffused bismuth increased by a factor of 103. In another series of experiments aiming at the study of the possibility of using iridium as a source of atoms and ions of bismuth, we performed the irradiation of $\operatorname{Ir}(111)$-C heated to $T=1550 \mathrm{~K}$ by a flux of bismuth atoms with a density of $v \approx 10^{14} \mathrm{sm}^{-2} \cdot \mathrm{s}^{-1}$ in a time of up to $t=30 \mathrm{~h}$. The values of the flux of bismuth atoms diffused from iridium at $T=2100 \mathrm{~K}$ after the exposure of Ir-C under aforementioned conditions for various exposure time periods are given in the Table 1 .

With the use of the equation shown in [1]-[3] [6], the activation energy of the bismuth diffusion into iridium was found to be $E_{n 1}=6.05 \pm 0.05 \mathrm{eV}$. The equation suggested in [1]-[3] [6] was also used to determine the activation energy of the bismuth diffusion from iridium. Since $\varphi_{\mathrm{Ir}(111)} \approx V_{\mathrm{Bi}}=5.785 \mathrm{~V}$, the coefficient of the surface ionization of bismuth atoms does not depend on temperature; hence, the $\ln I_{\mathrm{Bi}^{+}}=f(5040 / T)$ dependence is linear (Figure 2). By the slope of this dependence, the activation energy for bismuth diffusion from iridium is $E_{1 n}=6.3 \pm 0.1 \mathrm{eV}$. The amount of the intercalated and the diffused bismuth as a function of the positive potential upon irradiation of $\operatorname{Ir}(111)$-C heated to $T \leq 1800 \mathrm{~K}$ demonstrated that the intercalation of the graphite monolayer at on iridium is mainly performed by positive $\mathrm{Bi}^{+}$ions, which are formed on $\operatorname{Ir}(111)$-C from the incident flux by the mechanism of surface ionization. This is also confirmed by the fact that the direct determination of

Table 1. The values of the flux of bismuth atoms.

\begin{tabular}{cccccccc}
\hline$t, \mathrm{~h}$ & $\mathbf{0 . 5}$ & $\mathbf{1}$ & $\mathbf{1 . 5}$ & $\mathbf{2}$ & $\mathbf{2 . 5}$ & $\mathbf{3}$ \\
\hline$v \cdot 10^{-9} \mathrm{sm}^{-2} \cdot \mathrm{s}^{-1}$ & 4 & 10 & 15 & 32 & 50 & 55 \\
\hline
\end{tabular}




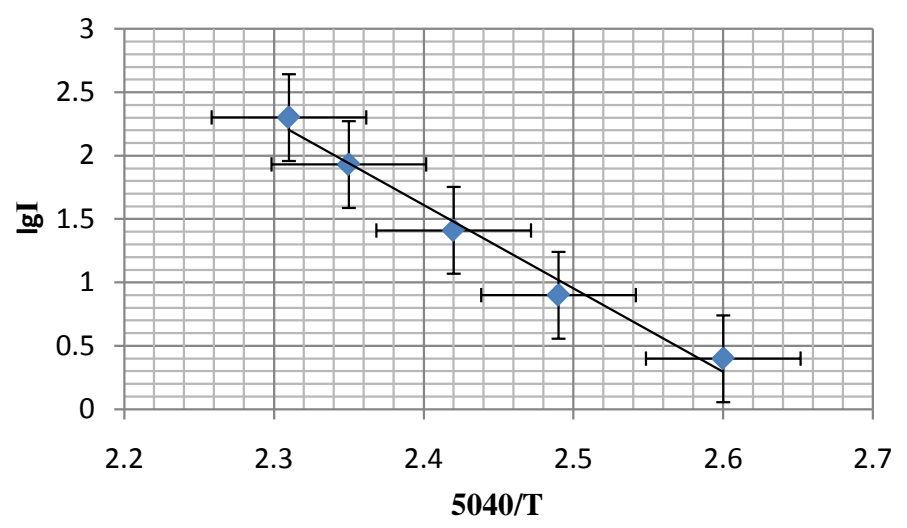

Figure 2. Logarithm of the ionic current of bismuth has a function of the reciprocal temperature, $\lg I_{\mathrm{Bi}^{+}}=f(1 / T)$.

the fraction of the bismuth flux $\delta_{\mathrm{Bi}}$ diffused into iridium upon the irradiation of $\operatorname{Ir}(111)$-C by a flux of bismuth atoms coincides with the magnitude of $\delta_{\mathrm{Bi}}$ determined from the comparison of the TDS data on the diffusion of bismuth and cesium into iridium (on the $\operatorname{Ir}(111)$-C surface, the cesium atoms are present in completely ionized state). The thermodesorption of $\mathrm{Bi}^{+}$ions from the $\operatorname{Ir}(111)-\mathrm{C}$ system before the vaporization of the graphite monolayer may be explained by the low radii of bismuth atoms and ions [9] $\left(r_{0}=1.70 \AA, r^{+}=0.74 \AA(+5 \mathrm{e}) r^{+}=\right.$ $0,96 \AA(+3 e)$ compared with the atomic and ionic radius of potassium $\left(r_{0}=2.31 \AA, r^{+}=1.33 \AA\right)$, cesium $\left(r_{0}=\right.$ $\left.2.62 \AA, r^{+}=1.69 \AA\right)$, samarium $\left(r_{0}=1.8 \AA, r^{+}=1 \AA\right)$, and barium $\left(r_{0}=2.17 \AA, r^{+}=1.35 \AA\right)$.

\section{Conclusion}

In summary, the presented work displays a new phenomenon of high efficiency diffusion into iridium of bismuth atoms adsorbed on the metal under a graphite monolayer. This phenomenon is used in practice as a method of active alloying with bismuth atoms of near surface layers of solid substances for the purpose of developing new materials which possess particular physicochemical characteristics of near surface zones.

\section{References}

[1] Tontegode, A.Y. and Yusifov, F.K. (1993) FTT, 35, 987-993.

[2] Tontegode, A.Y. and Yusifov, F.K. (1994) Poverhnost, 4, 20-24.

[3] Orujov, A.K., Dashdemirov, A.O. and Elchieva, A.K. (2010) Fizika Metals and Metallography, $109,13$.

[4] Tontegode, A.Ya. and Rutkov, E.V. (1993) UFN, 163, 57-74. http://dx.doi.org/10.3367/UFNr.0163.199311c.0057

[5] Orudzhov, A.K. and Dashdemirov, A.O. (2007) Diffusion of Na Atoms in Ir when Ir-C Irradiation Flux of Atoms Na. VII International Conference "Solid-State Chemistry and Modern Micro- and Nanosystems", Kislovodsk, 17-22 September 2007, 95-96.

[6] Orudzhov, A.K., Dashdemirov, A.O., Ahmedova, A.T. and Elchieva, A.K. (2005) Determination of the Activation Energy and the Activation Energy of Dissolution Release Atoms Ba, Sm, and into Iridium. Proceedings of the International Conference "Physics-2005", Baku, 7-9 June 2005, 183-185.

[7] Orudzhov, A.K. and Dashdemirov, A.O. (2009) FMM, 109, 53-57.

[8] Fomenko F.S. (1981) Emission Properties of Materials. Naukova Dumka, Kiev, 338.

[9] Grigor'ev, I.S. and Meilikhov, E.Z. (1991) Physical Value. Directory of Moscow. Energoizdat, Moscow, 1232. 